\title{
ATP-sensitive Potassium Channels Mediate Contraction-induced Attenuation of Sympathetic Vasoconstriction in Rat Skeletal Muscle
}

\author{
Gail D. Thomas, Jim Hansen, and Ronald G. Victor \\ Department of Internal Medicine, Molecular Cardiology Laboratories, The University of Texas Southwestern Medical Center, Dallas, \\ Texas 75235
}

\begin{abstract}
Sympathetic vasoconstriction is sensitive to inhibition by metabolic events in contracting rat and human skeletal muscle, but the underlying cellular mechanisms are unknown. In rats, this inhibition involves mainly $\alpha_{2}$-adrenergic vasoconstriction, which relies heavily on $\mathrm{Ca}^{2+}$ influx through voltage-dependent $\mathrm{Ca}^{2+}$ channels. We therefore hypothesized that contraction-induced inhibition of sympathetic vasoconstriction is mediated by ATP-sensitive potassium $\left(\mathrm{K}_{\mathrm{ATP}}\right)$ channels, a hyperpolarizing vasodilator mechanism that could be activated by some metabolic product(s) of skeletal muscle contraction. We tested this hypothesis in anesthetized rats by measuring femoral artery blood flow responses to lumbar sympathetic nerve stimulation or intraarterial hindlimb infusion of the specific $\alpha_{2}$-adrenergic agonist UK 14,304 during $\mathrm{K}_{\mathrm{ATP}}$ channel activation with diazoxide in resting hindlimb and during $K_{\mathrm{ATP}}$ channel block with glibenclamide in contracting hindlimb. The major new findings are twofold. First, like muscle contraction, pharmacologic activation of $\mathrm{K}_{\mathrm{ATP}}$ channels with diazoxide in resting hindlimb dose dependently attenuated the vasoconstrictor responses to either sympathetic nerve stimulation or intraarterial UK 14,304. Second, the large contraction-induced attenuation in sympathetic vasoconstriction elicited by nerve stimulation or UK 14,304 was partially reversed when the physiologic activation of $\mathrm{K}_{\mathrm{ATP}}$ channels produced by muscle contraction was prevented with glibenclamide. We conclude that contraction-induced activation of $K_{\text {ATP }}$ channels is a major mechanism underlying metabolic inhibition of sympathetic vasoconstriction in exercising skeletal muscle. $(J$. Clin. Invest. 1997. 99:2602-2609.) Key words: sympathetic nervous system $\cdot \alpha_{2}$ adrenergic vasoconstriction - muscle contraction $\bullet$ muscle blood flow $\bullet$ glibenclamide
\end{abstract}

\section{Introduction}

Activation of the sympathetic nervous system produces many of the cardiovascular adjustments during exercise, including

Address correspondence to Gail D. Thomas, Ph.D., University of Texas Southwestern Medical Center, 5323 Harry Hines Boulevard, Dallas, TX 75235-8573. Phone: 214-648-1443; FAX: 214-648-1450; E-mail: gthomas@ryburn.swmed.edu

Received for publication 11 December 1996 and accepted in revised form 10 March 1997.

J. Clin. Invest.

(C) The American Society for Clinical Investigation, Inc.

0021-9738/97/06/2602/08 \$2.00

Volume 99, Number 11, June 1997, 2602-2609 increases in blood pressure, heart rate, and regional vascular resistance. Although these adjustments match blood flow to the metabolic demands of exercising skeletal muscle, the underlying mechanisms by which this matching occurs remain poorly understood.

In quiescent skeletal muscle, sympathetic activation produces vasoconstriction, which is thought to optimize blood flow to the active muscles. However, the functional consequence of sympathetic activation in contracting skeletal muscle has been difficult to define. In isolated arterioles and in the microcirculation of quiescent skeletal muscle, $\alpha$-adrenergic vasoconstriction is sensitive to metabolic inhibition, such as that produced by experimental decreases in $\mathrm{pH}$ or $\mathrm{O}_{2}(1-4)$. We recently provided evidence that sympathetic vasoconstriction is also very sensitive to inhibition by metabolic events in contracting rat and human skeletal muscle $(5,6)$. This phenomenon, termed functional sympatholysis (7), negates an otherwise deleterious effect of sympathetic activation on skeletal muscle perfusion (5) and oxygenation (6). However, little is known about the cellular mechanisms involved in functional sympatholysis.

Our previous study in rats demonstrated that functional sympatholysis results from inhibition of mainly $\alpha_{2}$-adrenergic vasoconstriction, while $\alpha_{1}$-adrenergic vasoconstriction is well preserved (5). The reasons for this increased sensitivity of $\alpha_{2}$ mediated vasoconstriction to metabolic inhibition are not known, but may be linked to the underlying signal transduction pathway activated by $\alpha_{2}$-adrenergic receptors. In vascular smooth muscle, activation of $\alpha_{1}$-adrenergic receptors increases intracellular $\mathrm{Ca}^{2+}$ by releasing $\mathrm{Ca}^{2+}$ from internal stores as well as increasing membrane $\mathrm{Ca}^{2+}$ flux (8-10). In contrast, activation of $\alpha_{2}$-adrenergic receptors promotes influx of $\mathrm{Ca}^{2+}$ through voltage-dependent $\mathrm{Ca}^{2+}$ channels (8-10). Thus, membrane hyperpolarization and the consequent reduction in $\mathrm{Ca}^{2+}$ influx would be predicted to have a greater inhibitory effect on $\alpha_{2}$-rather than on $\alpha_{1}$-adrenergic vasoconstriction.

In general, hyperpolarization of vascular smooth muscle can be produced by the opening of membrane potassium channels (11). The ATP-sensitive potassium $\left(\mathrm{K}_{\mathrm{ATP}}\right)$ channel, one class of potassium channels found in vascular smooth muscle, is a particularly attractive candidate for mediating functional sympatholysis because the activity of this channel is sensitive to metabolic regulation $(11,12)$. Pharmacologic activation of $\mathrm{K}_{\mathrm{ATP}}$ channels has been shown to increase potassium efflux, causing membrane hyperpolarization and relaxation of vascular smooth muscle (13). There also is increasing evidence that endogenous vasodilators, such as adenosine (14-18), nitric oxide $(19,20)$, and prostacyclin $(21,22)$, act at least in part by opening $\mathrm{K}_{\mathrm{ATP}}$ channels. In addition to producing vasodilation, $\mathrm{K}_{\mathrm{ATP}}$ channel activation has been shown to attenuate $\alpha$-adrenergic vasoconstriction in intact coronary arteries (23) and in isolated vascular smooth muscle $(24,25)$. This inhibitory effect 
of $\mathrm{K}_{\mathrm{ATP}}$ channel activation was more effective on $\alpha_{2}$ - rather than on $\alpha_{1}$-mediated vasoconstriction (25).

We therefore hypothesized that activation of $\mathrm{K}_{\mathrm{ATP}}$ channels by some metabolic product of skeletal muscle contraction is a key mechanism by which sympathetic vasoconstriction, especially that mediated by $\alpha_{2}$-adrenergic receptors, is attenuated in exercising skeletal muscle. We tested this hypothesis in anesthetized rats by determining if $(a)$ pharmacologic activation of $\mathrm{K}_{\mathrm{ATP}}$ channels with diazoxide attenuates sympathetic vasoconstriction in resting skeletal muscle; and (b) pharmacologic inhibition of $\mathrm{K}_{\mathrm{ATP}}$ channels with glibenclamide restores sympathetic vasoconstriction in contracting skeletal muscle.

\section{Methods}

\section{Experimental preparation}

All the surgical and experimental protocols used in this study were approved by the Institutional Animal Care and Research Advisory Committee at the University of Texas Southwestern Medical Center. Female Sprague-Dawley rats (206-304 g; Charles River Laboratories, Wilmington, MA) were anesthetized with ketamine $(80 \mathrm{mg} / \mathrm{kg}$ i.p.) and $\alpha$-chloralose $(60 \mathrm{mg} / \mathrm{kg}$ i.v. followed by $10 \mathrm{mg} / \mathrm{kg}$ i.v. per h). Atropine sulfate $(0.5 \mathrm{mg} / \mathrm{kg}$ s.c. $)$ was administered, and a jugular vein and carotid artery were cannulated. The latter was used to measure arterial pressure. The cervical trachea was cannulated, and the rats were ventilated with room air and supplemental oxygen. Arterial blood gases were measured periodically (ABL-3; Radiometer, Copenhagen, Denmark) and kept within normal limits. Core temperature was maintained at $37^{\circ} \mathrm{C}$ with an external heat source.

A Doppler flow probe was placed around the left femoral artery to measure changes in blood flow velocity by recording the pulsatile and mean Doppler shifts in kilohertz using a VF-1 pulsed Doppler flow system (Crystal Biotech, Holliston, MA). Femoral vascular conductance was calculated as the mean Doppler shift divided by mean arterial pressure.

The left lumbar sympathetic chain was exposed via an anterior abdominal incision, isolated inferior to the renal artery, placed on bipolar platinum electrodes, and covered with silicone rubber (SilGel 604; Wacker-Chemie, Munich, Germany). The lumbar nerve was electrically stimulated (model S88; Grass Instruments, Quincy, MA) for $1 \mathrm{~min}$ at 2 or $5 \mathrm{~Hz}$ with 1-ms pulses of $5 \mathrm{~V}$. In some experiments, a small nonocclusive catheter was placed in the abdominal aorta, where it was situated proximal to the iliac bifurcation and was used for intraarterial hindlimb infusions of the selective $\alpha_{1}$-adrenergic agonist phenylephrine $(0.4-0.7 \mu \mathrm{g} / \mathrm{min})$ or the selective $\alpha_{2}$-adrenergic agonist UK $14,304(0.5-1.5 \mu \mathrm{g} / \mathrm{min})$.

The left sciatic nerve was exposed in the region of the sciatic notch, covered with warm mineral oil, and affixed to stimulating electrodes. The left gastrocnemius-plantaris muscles were dissected free of surrounding muscles and connected to a force-displacement transducer (FT-10; Grass Instruments) via the calcaneal tendon. To produce intermittent, tetanic contractions, the sciatic nerve was stimulated (model S88; Grass Instruments) at two to three times the motor threshold voltage with $100-\mathrm{ms}$ trains of pulses $(100 \mathrm{~Hz}, 0.2 \mathrm{~ms}$ duration) at a rate of 30 trains $/ \mathrm{min}$. Contraction periods of 10-20 min were separated by rest periods of at least $20 \mathrm{~min}$.

\section{Drugs}

UK 14,304 (5-bromo- $N$-(4,5-dihydro-1H-imidazol-2-yl)-6-quinoxalinamine; RBI, Natick, MA) was dissolved initially in DMSO to make a $10 \mathrm{mg} / \mathrm{ml}$ stock solution, and then further diluted to $10 \mu \mathrm{g} / \mathrm{ml}$ in $0.9 \%$ saline. Final DMSO concentration was $0.1 \%$. Phenylephrine hydrochloride was dissolved in $0.9 \%$ saline. Diazoxide (Sigma Immunochemicals, St. Louis, MO) was dissolved in $1 \mathrm{M} \mathrm{NaOH}$ at a concentration of $83 \mathrm{mg} / \mathrm{ml}$, and was diluted to final concentration in $0.9 \%$ saline. Glibenclamide (RBI) was dissolved in $0.1 \mathrm{M} \mathrm{NaOH}$ under continuous sonication at a concentration of $25 \mathrm{mg} / \mathrm{ml}$, and was then diluted to $5 \mathrm{mg} / \mathrm{ml}$ in $5 \%$ dextrose solution.

\section{Experimental protocols}

Protocol 1: Effect of pharmacologic activation of $K_{A T P}$ channels in resting skeletal muscle on sympathetic vasoconstriction. To determine whether activation of $\mathrm{K}_{\mathrm{ATP}}$ channels in resting hindlimb could attenuate $\alpha$-adrenergic vasoconstriction, we measured the mean arterial pressure and femoral blood flow velocity responses to lumbar sympathetic nerve stimulation at 2 and $5 \mathrm{~Hz}(n=6)$ and to intraarterial hindlimb infusion of the $\alpha_{2}$-adrenergic agonist UK 14,304 $(n=6)$ or the $\alpha_{1}$-adrenergic agonist phenylephrine $(n=4)$ during infusion of cumulative doses $\left(5,10,15,20\right.$, and $25 \mathrm{mg} / \mathrm{kg}$ i.v.) of the $\mathrm{K}_{\text {ATP }}$ channel opener diazoxide. Each dose of diazoxide was infused in a volume of $1 \mathrm{ml}$ during $15 \mathrm{~min}$. To control for a possible nonspecific effect of vasodilation per se on sympathetic vasoconstriction, in a separate group of six rats, we measured the mean arterial pressure and femoral blood flow velocity responses to lumbar sympathetic nerve stimulation $(5 \mathrm{~Hz})$ during intraarterial hindlimb infusion of isoproterenol $(0.12 \mu \mathrm{g} / \mathrm{min})$ and during the peak reactive hyperemia after release of a 60 -s occlusion of the left iliac artery.

Protocol 2: Effect of pharmacologic blockade of $K_{A T P}$ channels on the contraction-induced attenuation of sympathetic vasoconstriction. To determine whether blocking $\mathrm{K}_{\mathrm{ATP}}$ channels in contracting skeletal muscle could restore the vasoconstrictor response to sympathetic stimulation, we measured the mean arterial pressure and femoral blood flow velocity responses to lumbar sympathetic nerve stimulation $(5 \mathrm{~Hz})$ in one group of rats $(n=7)$ or to intraarterial hindlimb infusion of the $\alpha_{2}$ agonist UK 14,304 in another group of rats $(n=6)$ during hindlimb contraction before and after infusion of the $\mathrm{K}_{\mathrm{ATP}}$ channel blocker glibenclamide $(20 \mathrm{mg} / \mathrm{kg}$ i.v.). Sympathetic nerve stimulation and UK 14,304 infusions were performed when the force produced by the contracting muscles had declined to $\sim 50 \%$ of the initial value. Glibenclamide was infused in a volume of $\sim 1 \mathrm{ml}$ during $15 \mathrm{~min}$. Control experiments using the same protocol were performed in five more rats before and after infusion of the vehicle for glibenclamide.

Protocol 2a: Comparison of functional sympatholysis during two consecutive contractions. In Protocol 2, because of the long-lasting effects of glibenclamide, the first contraction was always performed in the absence of glibenclamide, while the second contraction was always performed in the presence of glibenclamide. The aim of this protocol was to determine if any changes that we observed after glibenclamide could be explained simply by an order effect. To do so, we measured the mean arterial pressure and femoral blood flow responses to lumbar sympathetic nerve stimulation $(5 \mathrm{~Hz})$ in eight rats during two consecutive contraction periods in the absence of any intervention.

Protocol 2b: Effect of attenuated active hyperemia on functional sympatholysis. To determine if the attenuated functional sympatholysis that we observed after glibenclamide could be explained by the effect of glibenclamide to reduce active hyperemia, we measured the mean arterial pressure and femoral blood flow responses to lumbar sympathetic nerve stimulation $(5 \mathrm{~Hz})$ in six rats during two consecutive contraction periods. Blood flow was allowed to increase normally in response to contraction during the first contraction period, but was reduced by $\sim 50 \%$ by partial mechanical occlusion of the left iliac artery during the second contraction period.

\section{Data analysis}

Statistical analysis was performed using repeated measures ANOVA with Dunnett's post hoc test to compare responses to baseline values. To detect differences within each group in the responses to sympathetic nerve stimulation (or UK 14,304 infusion) and to hindlimb contraction, performed alone and in combination, two-factor repeated measures ANOVA was performed. Differences were considered statistically significant when $P<0.05$. Results are expressed as mean \pm SE. 
Table I. Hemodynamic Responses to Infusion of Diazoxide

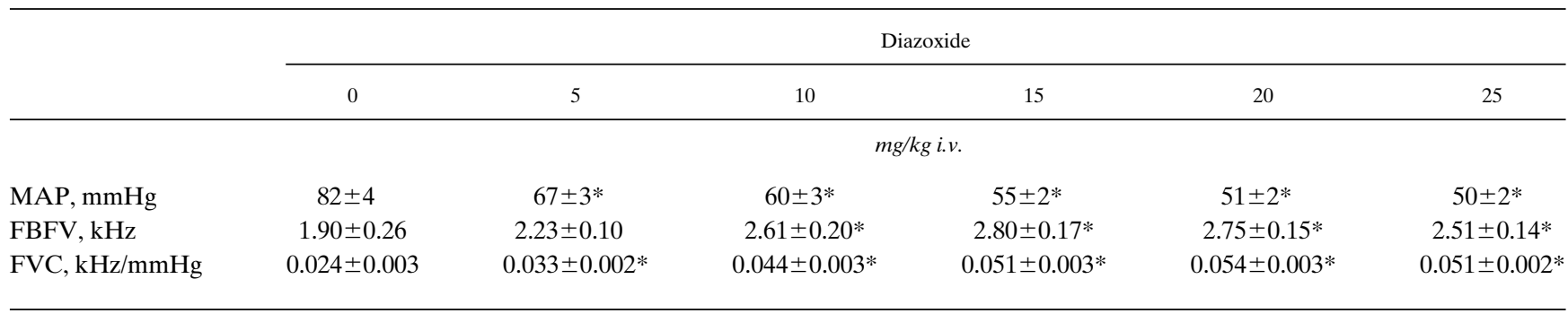

Values are mean \pm SE; $n=12$ rats. MAP, mean arterial pressure; FBFV, femoral blood flow velocity; FVC, femoral vascular conductance. ${ }^{*} P<0.05$ vs. $0 \mathrm{mg} / \mathrm{kg}$.

\section{Results}

Pharmacologic activation of $K_{A T P}$ channels with diazoxide attenuates sympathetic vasoconstriction in resting skeletal muscle (Protocol 1). The hemodynamic responses to infusion of the $\mathrm{K}_{\text {ATP }}$ channel opener diazoxide are presented in Table I. Diazoxide dose dependently decreased MAP, increased femoral blood flow velocity, and increased vascular conductance. In the absence of diazoxide, infusion of the $\alpha_{2}$ agonist UK 14,304 or the $\alpha_{1}$ agonist phenylephrine elicited robust decreases in femoral blood flow velocity and vascular conductance ( $-51 \pm 3 \%$, UK 14,$304 ;-59 \pm 2 \%$, phenylephrine). A moderate dose of diazoxide $(15 \mathrm{mg} / \mathrm{kg})$ significantly attenuated the decrease in vascular conductance in response to UK 14,304 ( $-23 \pm 5 \%, P<0.05$ vs. before diazoxide) (Fig. 1$)$, but not to phenylephrine $(-43 \pm 8 \%)$. In contrast, a high dose of diazoxide $(25 \mathrm{mg} / \mathrm{kg})$ significantly attenuated the decreases in vascular conductance in response to both UK 14,304 $(-13 \pm 4 \%, P<$ 0.05 vs. before diazoxide) and phenylephrine $(-21 \pm 6 \%, P<$ 0.05 vs. before diazoxide).

The decreases in femoral vascular conductance elicited by sympathetic nerve stimulation also were significantly attenuated by diazoxide at doses of $15 \mathrm{mg} / \mathrm{kg}$ and greater (Fig. 2). In contrast, the vasoconstrictor responses to sympathetic nerve stimulation were well preserved during comparable hindlimb vasodilation produced by intraarterial infusion of isoproterenol, as well as during peak reactive hyperemia after a 60 -s occlusion of the iliac artery, which were used as internal vasodilator controls (Fig. 3). Although $\mathrm{K}_{\mathrm{ATP}}$ channels have been implicated in the vasodilator responses to isoproterenol (15, $26,27)$ and during reactive hyperemia $(28,29)$, we determined in preliminary experiments that in our rat model, glibenclamide $(20 \mathrm{mg} / \mathrm{kg}$ i.v. ) did not attenuate the increases in femoral blood flow velocity during intraarterial isoproterenol $(+1.27 \pm 0.34 \mathrm{kHz}$ before vs. $+1.35 \pm 0.55 \mathrm{kHz}$ after glibenclamide, $P>0.05, n=5$ ) or the peak reactive hyperemic response to release of a 60 -s iliac artery occlusion $(+1.89 \pm 0.72$ $\mathrm{kHz}$ before vs. $+1.83 \pm 0.64 \mathrm{kHz}$ after glibenclamide, $P>0.05$, $n=5$ ). However, the overall duration of the reactive hyperemic response was reduced by glibenclamide $(116 \pm 16 \mathrm{~s}$ before vs. $84 \pm 21$ s after, $P<0.05)$.

Pharmacologic blockade of $K_{A T P}$ channels with glibenclamide partially restores sympathetic vasoconstriction in contracting skeletal muscle (Protocol 2). The hemodynamic responses to unilateral, intermittent tetanic contractions of the gastrocnemius-plantaris muscles before and after infusion of the $\mathrm{K}_{\mathrm{ATP}}$ channel blocker glibenclamide $(20 \mathrm{mg} / \mathrm{kg}$ i.v.) are presented in Table II. In the absence of glibenclamide, hindlimb contraction significantly increased femoral blood flow velocity and vascular conductance. Glibenclamide increased baseline mean arterial pressure by $14 \pm 4 \mathrm{mmHg}(P<0.05)$, but had no significant effect on baseline femoral blood flow velocity or conductance. In contrast, in these same rats, glibenclamide significantly attenuated the contraction-induced increases in femoral blood flow velocity $(+151 \pm 14 \%$ before vs. $+93 \pm 18 \%$ after, $P<0.05)$ and conductance $(+148 \pm 12 \%$ before vs. $+82 \pm 18 \%$ after, $P<0.05)$. The force produced by the contracting muscles was similar before and after glibenclamide (peak force
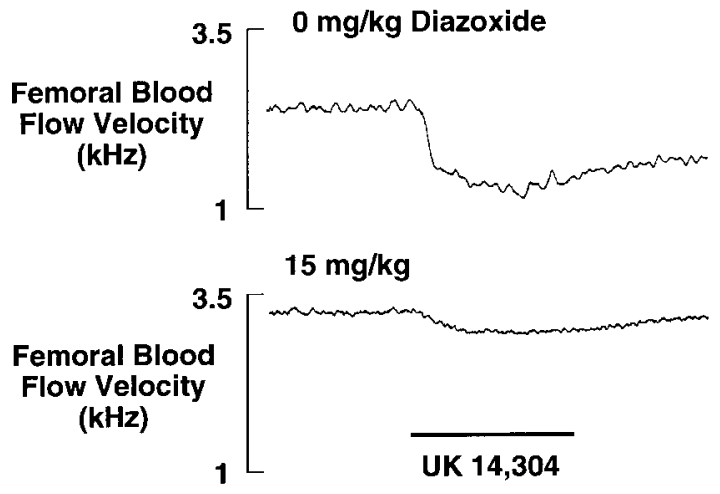

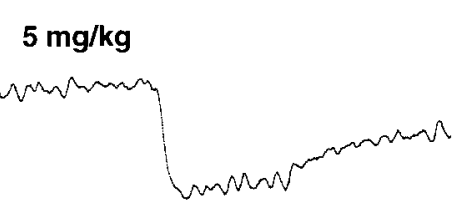

$20 \mathrm{mg} / \mathrm{kg}$

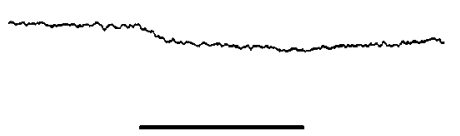

UK 14,304

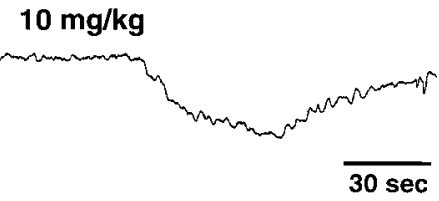

$25 \mathrm{mg} / \mathrm{kg}$

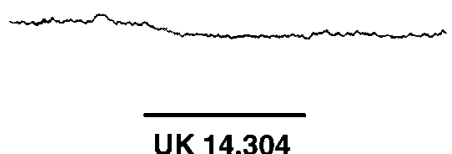

Figure 1. Segments of an original record showing the mean femoral artery blood flow velocity responses to intraarterial hindlimb infusion of the $\alpha_{2}$-adrenergic agonist UK 14,304 during intravenous infusion of increasing doses of the $\mathrm{K}_{\mathrm{ATP}}$ channel opener diazoxide. In resting skeletal muscle, the vasoconstrictor response to UK 14,304 was significantly attenuated by doses of diazoxide $\geq 15 \mathrm{mg} / \mathrm{kg}$. 

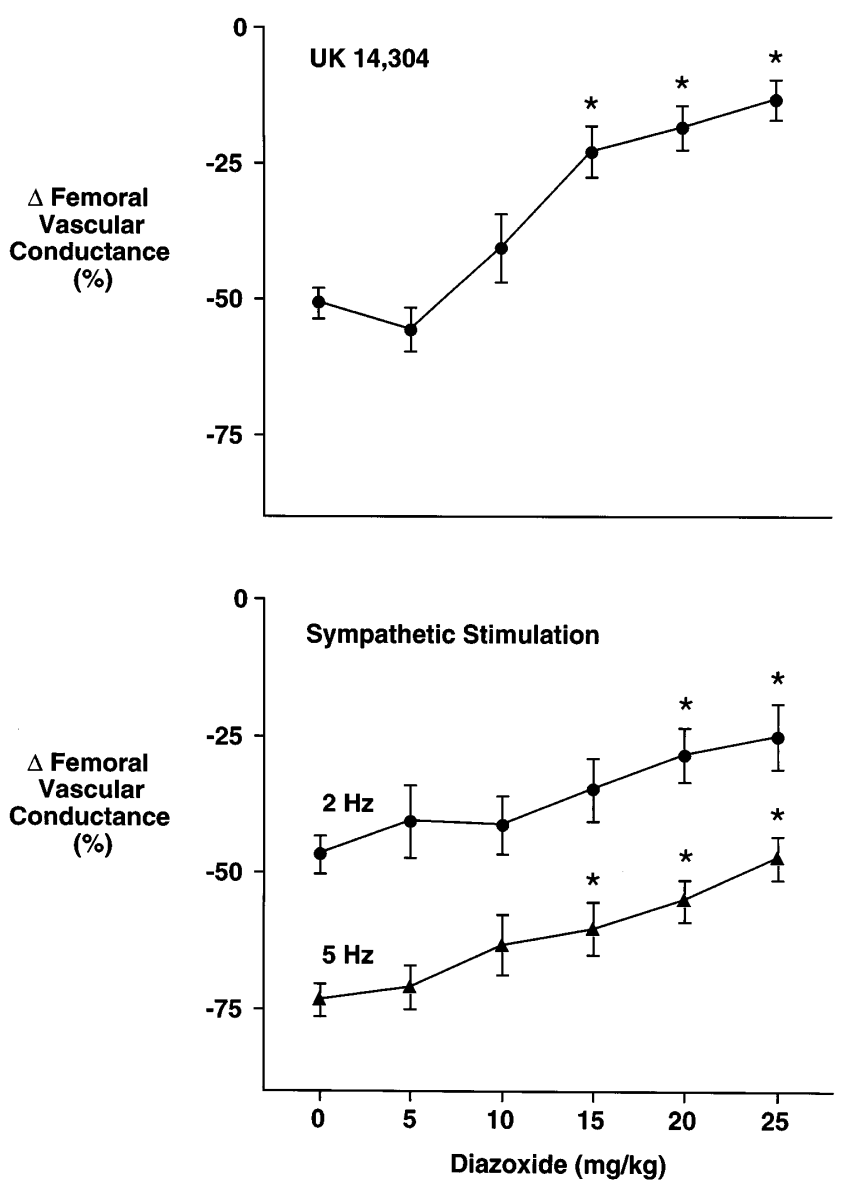

Figure 2. Summary data showing the effect of increasing doses of diazoxide on the decreases in femoral vascular conductance elicited by intraarterial hindlimb infusion of the $\alpha_{2}$-adrenergic agonist UK $14,304(n=6)$ and by two different intensities of lumbar sympathetic nerve stimulation $(2 \mathrm{~Hz}, n=4 ; 5 \mathrm{~Hz}, n=6)$ in resting skeletal muscle. At doses of $15 \mathrm{mg} / \mathrm{kg}$ and greater, diazoxide significantly inhibited the vasoconstrictor responses to UK 14,304 and to sympathetic stimulation. ${ }^{*} P<0.05$ vs. $0 \mathrm{mg} / \mathrm{kg}$ diazoxide.

$1.8 \pm 0.1 \mathrm{~kg}$ before vs. $1.7 \pm 0.1 \mathrm{~kg}$ after glibenclamide, $P>$ 0.05). The vehicle for glibenclamide had no effect on the hemodynamic responses to contraction (Table II).

In resting skeletal muscle, both intraarterial hindlimb infu- sion of the $\alpha_{2}$-adrenergic agonist UK 14,304 and lumbar sympathetic nerve stimulation elicited robust vasoconstrictor responses that were similar before and after glibenclamide (see Fig. 5). UK 14,304 decreased femoral vascular conductance by $0.015 \pm 0.001$ and $0.013 \pm 0.002 \mathrm{kHz} / \mathrm{mmHg}$ before and after glibenclamide $(P>0.05)$, respectively, while sympathetic stimulation decreased conductance by $0.016 \pm 0.002$ and $0.012 \pm 0.002$ $\mathrm{kHz} / \mathrm{mmHg}$ before and after glibenclamide $(P>0.05)$, respectively. Contraction of the gastrocnemius-plantaris muscles greatly attenuated these vasoconstrictor responses before glibenclamide (Figs. 4 and 5). The magnitude of this contraction-induced attenuation of sympathetic vasoconstriction was significantly reduced after glibenclamide (Figs. 4 and 5). Compared to resting muscle, contraction attenuated the decreases in femoral vascular conductance in response to UK 14,304 and to sympathetic stimulation by 65 and $50 \%$, respectively, before glibenclamide and by 31 and $35 \%$, respectively, after glibenclamide $(P<0.05$ vs. before glibenclamide). The vehicle for glibenclamide had no effect on the contraction-induced attenuation of sympathetic vasoconstriction (Fig. 6).

Sympathetic vasoconstriction is attenuated similarly during two consecutive contraction periods in the absence of any intervention (Protocol $2 a$ ). Unilateral hindlimb contraction elicited similar increases in femoral blood flow velocity and vascular conductance during two consecutive contraction periods (Table II). The contraction-induced attenuation of sympathetic vasoconstriction was also similar during the two contraction periods (Fig. 6).

Attenuated active hyperemia does not restore sympathetic vasoconstriction in contracting skeletal muscle (Protocol 2b). Sympathetic vasoconstriction was significantly attenuated in the contracting hindlimb when femoral blood flow velocity increased normally in response to muscle contraction $(+160 \pm$ $14 \%$; Fig. 6). In these same rats, sympathetic vasoconstriction also was attenuated when the hyperemic response to contraction was reduced by $\sim 50 \%$ with partial vascular occlusion (femoral blood flow velocity increased by $71 \pm 15 \%$; Fig. 6).

\section{Discussion}

We have previously demonstrated that sympathetic vasoconstriction is very sensitive to metabolic inhibition during voluntary forearm exercise in conscious humans (6) and during electrically induced hindlimb contractions in anesthetized rats (5).

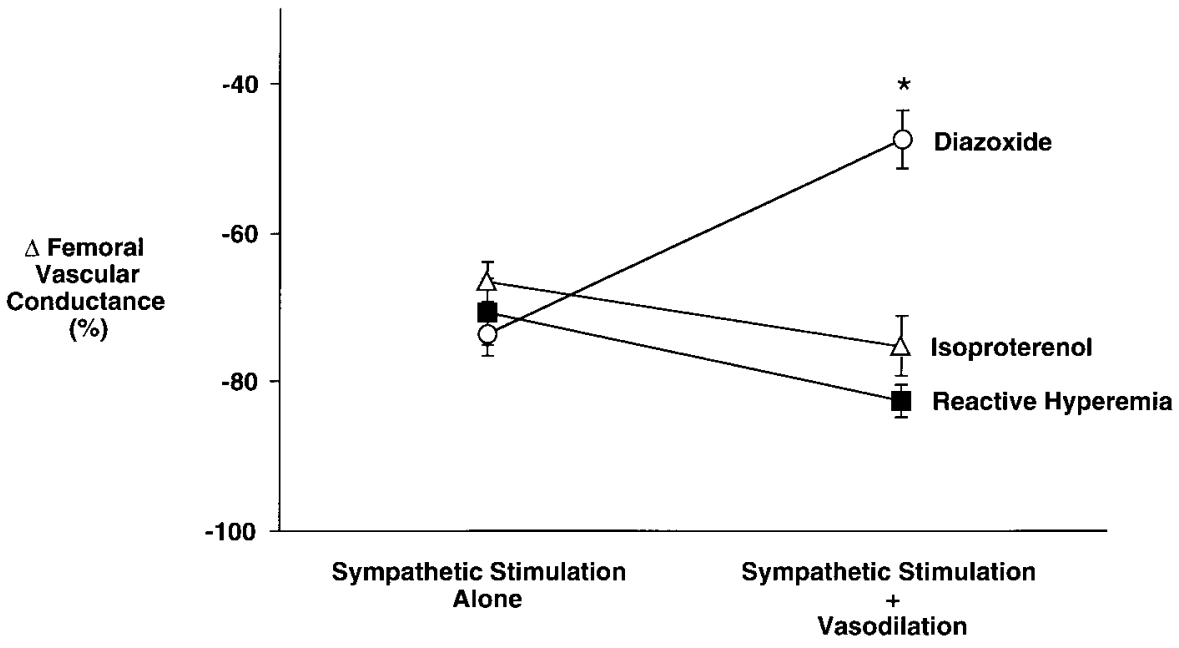

Figure 3. Summary data illustrating the decreases in femoral vascular conductance elicited by lumbar sympathetic nerve stimulation in resting skeletal muscle before and during comparable vasodilation produced by diazoxide infusion $(n=6)$, reactive hyperemia $(n=6)$, and isoproterenol infusion $(n=6)$. Of the three vasodilator stimuli used, diazoxide was the only one that significantly attenuated sympathetic vasoconstriction. ${ }^{*} P<0.05$ vs. sympathetic stimulation alone. 
Table II. Hemodynamic Responses to Unilateral Contractions of the Gastrocnemius-Plantaris Muscles before and after Treatment with Glibenclamide

\begin{tabular}{|c|c|c|c|c|c|c|}
\hline \multirow[b]{2}{*}{ Group } & \multicolumn{3}{|c|}{ Contraction alone } & \multicolumn{3}{|c|}{ Contraction + intervention } \\
\hline & Rest & Contraction & $\Delta$ & Rest & Contraction & $\Delta$ \\
\hline & \multicolumn{6}{|c|}{ Mean arterial pressure } \\
\hline & \multicolumn{6}{|c|}{$m m H g$} \\
\hline Glibenclamide & $78 \pm 4$ & $78 \pm 2$ & $+0 \pm 3$ & $92 \pm 4^{\ddagger}$ & $98 \pm 4^{\ddagger}$ & $+6 \pm 2^{\ddagger}$ \\
\hline Vehicle & $69 \pm 6$ & $81 \pm 10$ & $+12 \pm 4$ & $68 \pm 8$ & $81 \pm 9$ & $+12 \pm 3$ \\
\hline \multirow[t]{3}{*}{ No intervention } & $70 \pm 4$ & $75 \pm 4$ & $+6 \pm 2$ & $70 \pm 4$ & $77 \pm 4$ & $+7 \pm 2$ \\
\hline & \multicolumn{6}{|c|}{ Femoral blood flow velocity } \\
\hline & \multicolumn{6}{|c|}{$k H z$} \\
\hline Glibenclamide & $2.00 \pm 0.23$ & $4.73 \pm 0.41 *$ & $+2.73 \pm 0.25$ & $2.00 \pm 0.22$ & $3.58 \pm 0.28^{* \neq}$ & $+1.58 \pm 0.20^{\ddagger}$ \\
\hline Vehicle & $1.26 \pm 0.35$ & $3.13 \pm 0.58 *$ & $+2.02 \pm 0.34$ & $1.36 \pm 0.26$ & $3.14 \pm 0.37 *$ & $+1.99 \pm 0.15$ \\
\hline \multirow[t]{3}{*}{ No intervention } & $1.65 \pm 0.20$ & $4.49 \pm 0.48^{*}$ & $+2.85 \pm 0.39$ & $2.24 \pm 0.24^{\ddagger}$ & $4.71 \pm 0.35^{*}$ & $+2.47 \pm 0.28$ \\
\hline & \multicolumn{6}{|c|}{ Femoral vascular conductance } \\
\hline & \multicolumn{6}{|c|}{$\mathrm{kHz} / \mathrm{mmHg}$} \\
\hline Glibenclamide & $0.025 \pm 0.002$ & $0.060 \pm 0.005^{*}$ & $+0.035 \pm 0.003$ & $0.022 \pm 0.002$ & $0.036 \pm 0.002 * \neq$ & $+0.015 \pm 0.002^{\ddagger}$ \\
\hline Vehicle & $0.020 \pm 0.006$ & $0.041 \pm 0.009 *$ & $+0.021 \pm 0.003$ & $0.022 \pm 0.005$ & $0.041 \pm 0.007 *$ & $+0.019 \pm 0.003$ \\
\hline No intervention & $0.024 \pm 0.003$ & $0.060 \pm 0.007 *$ & $+0.036 \pm 0.005$ & $0.032 \pm 0.003^{\ddagger}$ & $0.061 \pm 0.003 *$ & $+0.029 \pm 0.003$ \\
\hline
\end{tabular}

Values are means \pm SE. Glibenclamide, $n=13$; vehicle, $n=5$; no intervention, $n=8$. In all groups, the first contraction period was performed in the absence of any intervention. The second contraction period was performed in the presence of glibenclamide ( $20 \mathrm{mg} / \mathrm{kg}$, i.v. $)$ or an equivalent volume of the vehicle for glibenclamide, or in the absence of both glibenclamide and vehicle. ${ }^{*} P<0.05$ vs. rest; ${ }^{\ddagger} P<0.05$ vs. contraction alone.

We now implicate a major role for $\mathrm{K}_{\mathrm{ATP}}$ channel activation in this process. The major new findings are twofold. First, like muscle contraction, pharmacologic activation of $\mathrm{K}_{\mathrm{ATP}}$ channels in resting hindlimb with diazoxide attenuated sympathetic vasoconstriction in a dose-dependent manner. Second, the large contraction-induced attenuation of sympathetic vasoconstric- tion was partially reversed when the physiologic activation of $\mathrm{K}_{\mathrm{ATP}}$ channels produced by muscle contraction was prevented with glibenclamide. From these observations, we conclude that contraction-induced activation of $\mathrm{K}_{\mathrm{ATP}}$ channels is a major mechanism underlying metabolic inhibition of sympathetic vasoconstriction in exercising skeletal muscle.

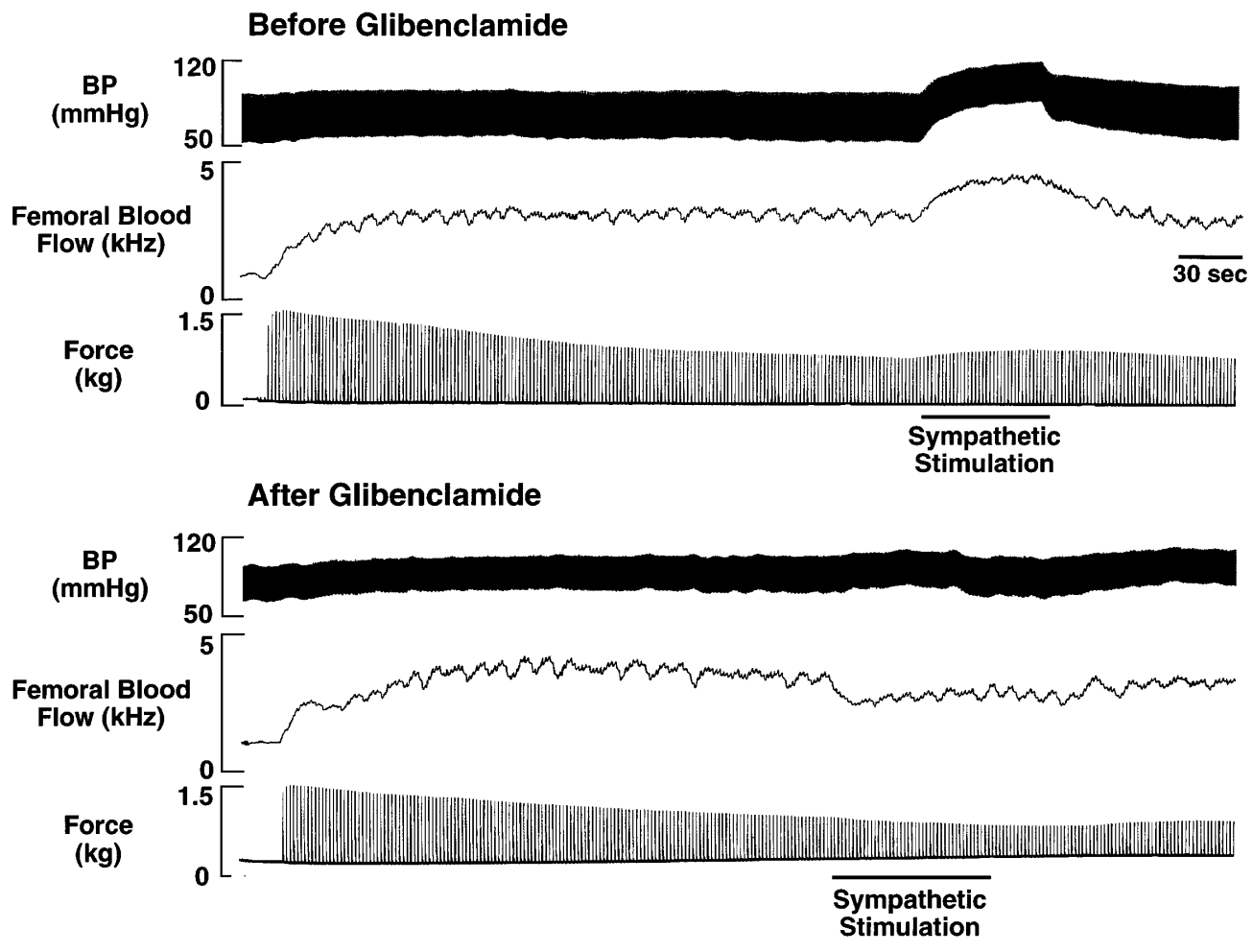

Figure 4. Segments of an original record from one rat showing the arterial pressure and femoral blood flow velocity responses to lumbar sympathetic nerve stimulation during hindlimb contractions before (top) and after (bottom) blockade of $\mathrm{K}_{\mathrm{ATP}}$ channels with glibenclamide. Before glibenclamide, sympathetic vasoconstriction in the contracting muscles was greatly attenuated (i.e., functional sympatholysis), as indicated by the increase, rather than decrease, in femoral blood flow velocity elicited by sympathetic nerve stimulation. In this same rat, after glibenclamide, sympathetic nerve stimulation elicited a decrease in femoral blood flow velocity, indicating that sympathetic vasoconstriction was partially restored in the contracting muscles. 

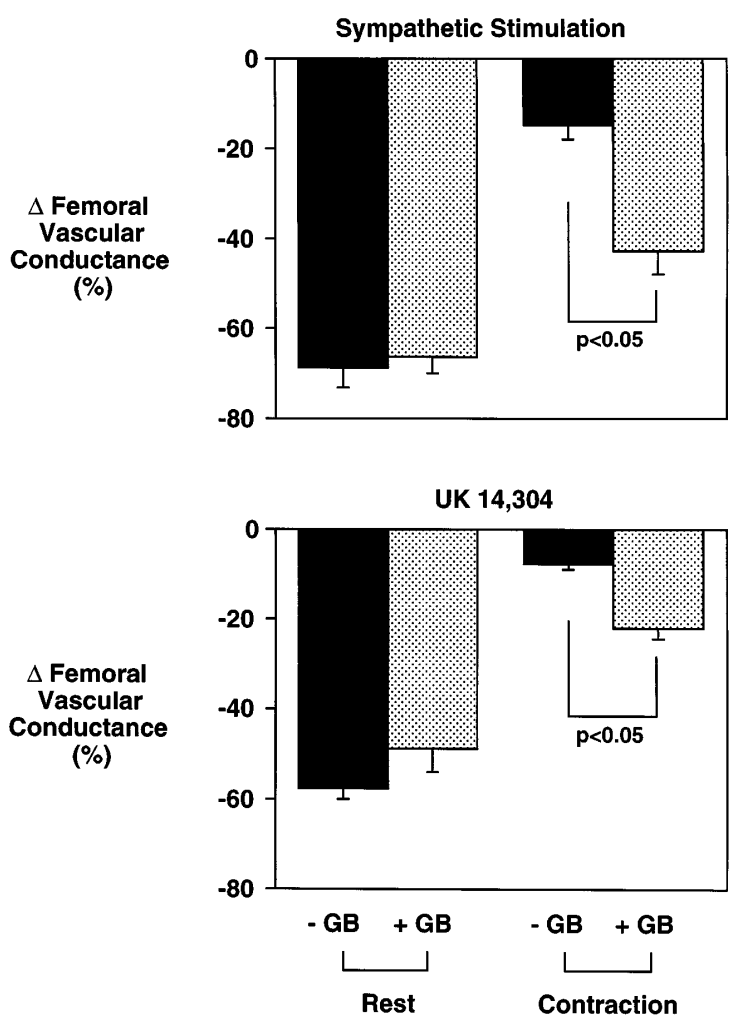

Figure 5. Summary data showing the decreases in femoral vascular conductance in response to lumbar sympathetic nerve stimulation $(n=7)$ and to the $\alpha_{2}$-adrenergic agonist UK 14,304 $(n=6)$ in resting and contracting hindlimb before and after glibenclamide $(G B)$. Sympathetic stimulation and UK 14,304 both produced robust vasoconstrictor responses in resting muscle that were significantly attenuated during muscle contraction. While glibenclamide did not affect these vasoconstrictor responses in resting muscle, it did significantly enhance the vasoconstrictor responses to sympathetic nerve stimulation and UK 14,304 in contracting muscle.

In resting skeletal muscle, the diazoxide-induced attenuation of sympathetic vasoconstriction appears to be a specific effect of $\mathrm{K}_{\mathrm{ATP}}$ channel activation, because sympathetic vasoconstriction was well preserved during either peak reactive hyperemia or isoproterenol infusion, which were used as internal vasodilator controls. Although $\mathrm{K}_{\mathrm{ATP}}$ channel activation has been implicated in these latter two responses by other investigators $(15,26-29)$, we found in the present study that the peak vasodilation achieved during reactive hyperemia and isoproterenol infusion was not attenuated by $\mathrm{K}_{\mathrm{ATP}}$ channel block with glibenclamide. In contrast, the vasodilation produced by diazoxide was significantly attenuated by the same dose of glibenclamide. Furthermore, we demonstrated previously that in the resting rat hindlimb, sympathetic vasoconstriction is unaffected by intraarterial hydralazine (5), a vasodilator that is not thought to open $\mathrm{K}_{\mathrm{ATP}}$ channels $(30,31)$.

Activation of $\mathrm{K}_{\mathrm{ATP}}$ channels could attenuate sympathetic vasoconstriction either by reducing prejunctional release of norepinephrine or by interfering with the postjunctional actions of norepinephrine on vascular $\alpha$-adrenergic receptors. While there is precedent for both mechanisms of action (23, $32,33)$, the present finding that diazoxide attenuated the vasoconstrictor responses to intraarterial hindlimb infusion of the
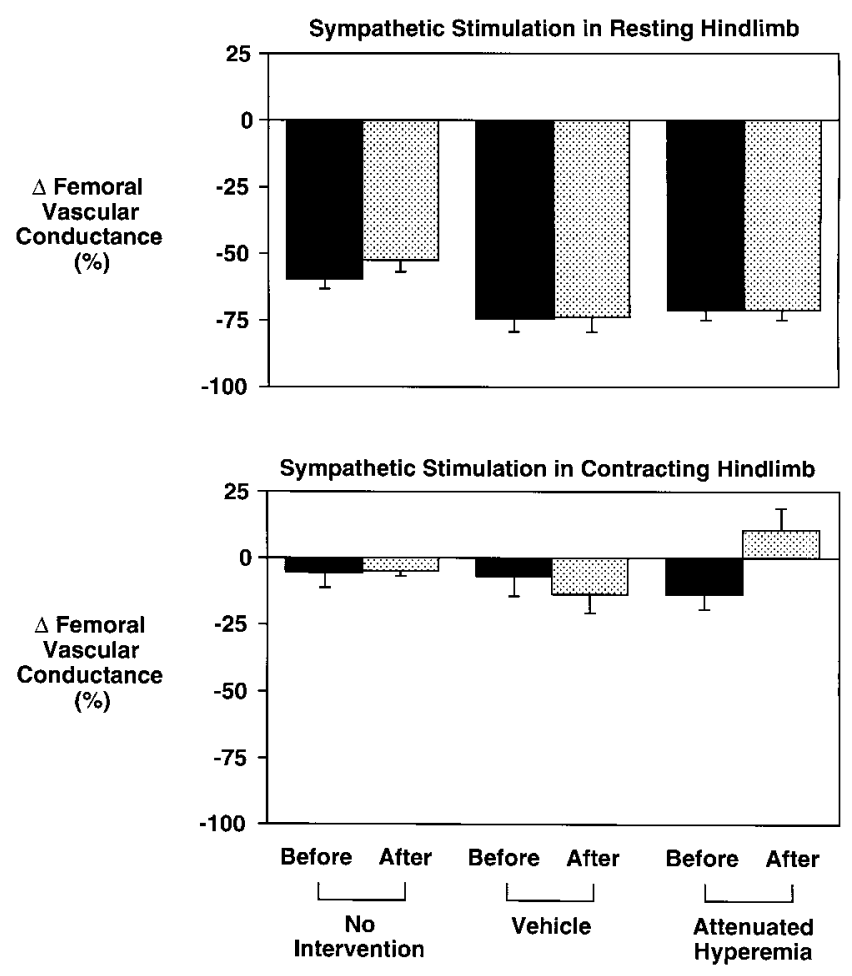

Figure 6. Summary data showing the changes in femoral vascular conductance in response to lumbar sympathetic nerve stimulation in resting (top) and contracting (bottom) hindlimb during two consecutive contraction periods in the absence of any intervention $(n=8)$, before and after infusion of the vehicle for glibenclamide $(n=5)$, and when active hyperemia was attenuated by $\sim 50 \%$ by partial occlusion of the iliac artery $(n=6)$. None of these interventions had any effect on sympathetic vasoconstriction in resting hindlimb. In all three groups, the sympathetically mediated decreases in vascular conductance were attenuated similarly during hindlimb contraction before and after each intervention.

$\alpha_{2}$-adrenergic agonist UK 14,304 , as well as to sympathetic nerve stimulation, points to a postjunctional site of action. This is important because we previously demonstrated that a postjunctional mechanism also mediates the metabolic inhibition of sympathetic vasoconstriction in contracting hindlimb muscle, mainly by attenuating $\alpha_{2}$-mediated vasoconstriction (5). Consistent with this previous data is our finding in the present study that diazoxide also has a greater inhibitory effect on $\alpha_{2}$ than on $\alpha_{1}$-adrenergic vasoconstriction.

Indeed, the salient feature of the present experiments is the demonstration that such contraction-induced metabolic inhibition of sympathetic vasoconstriction is quite sensitive to modulation by changes in the activity of $\mathrm{K}_{\mathrm{ATP}}$ channels. The same intensity of muscle contraction led to much less metabolic inhibition of sympathetic vasoconstriction when $\mathrm{K}_{\mathrm{ATP}}$ channel activation was prevented with the $\mathrm{K}_{\mathrm{ATP}}$ channel blocker glibenclamide. This was the case, regardless of whether sympathetic vasoconstriction was elicited by lumbar nerve stimulation or by intraarterial infusion of an $\alpha_{2}$ agonist, which localizes this effect of glibenclamide to a postjunctional site of action. In resting skeletal muscle, however, sympathetic vasoconstriction was unaffected by glibenclamide, suggesting that blocking $\mathrm{K}_{\mathrm{ATP}}$ channels has a greater effect on sympathetic vasoconstriction 
when the open probability of the channels is high, as in contracting muscle, than when the open probability is low, as in resting muscle.

This latter observation may provide some important clues as to the mechanism underlying the observed interaction between $\mathrm{K}_{\mathrm{ATP}}$ channel activation and $\alpha_{2}$-adrenergic vasoconstriction. Studies in isolated arterioles have advanced the hypothesis that $\alpha_{2}$-adrenergic receptors are directly coupled to $\mathrm{K}_{\mathrm{ATP}}$ channels such that $\mathrm{K}_{\mathrm{ATP}}$ channel closure is an integral step in the process of $\alpha_{2}$-adrenergic vasoconstriction (25). Pretreatment with glibenclamide completely occluded the vasoconstrictor response to subsequent challenge with UK 14,304 (25). Our data, however, do not support this hypothesis. In resting rat hindlimb muscle, glibenclamide pretreatment did not attenuate the vasoconstrictor response to subsequent challenge with UK 14,304. In contracting hindlimb muscle, glibenclamide pretreatment augmented the vasoconstrictor response to subsequent challenge with UK 14,304. Even if $\alpha_{2}$-adrenergic vasoconstriction and $\mathrm{K}_{\mathrm{ATP}}$ channel activation are not directly coupled, the two processes could exert opposing influences on vasomotor tone. The hyperpolarizing effect of $\mathrm{K}_{\mathrm{ATP}}$ channel activation may, for example, act to reduce $\mathrm{Ca}^{2+}$ influx through voltage-dependent $\mathrm{Ca}^{2+}$ channels in vascular smooth muscle. This would be expected to have a particularly potent inhibitory effect on $\alpha_{2}$-mediated vasoconstriction, which is thought to rely heavily on $\mathrm{Ca}^{2+}$ influx through the cell membrane rather than on release of $\mathrm{Ca}^{2+}$ from intracellular stores (8-10). Experimental evidence for a greater inhibitory effect of $\mathrm{K}_{\mathrm{ATP}}$ channel activation on vasoconstrictor agents that use extracellular rather than intracellular calcium has previously been provided in isolated, endothelial-denuded coronary arteries (34).

In our experiments, glibenclamide also attenuated active hyperemia, which is consistent with previous studies in the canine diaphragm $(35,36)$ and hamster cremaster muscle $(37)$. We therefore considered the possibility that the attenuated active hyperemia may have contributed to the enhanced sympathetic vasoconstrictor response in the glibenclamide-treated animals. However, this was not the case because sympathetic vasoconstriction was not enhanced (i.e., functional sympatholysis persisted) when we used partial mechanical occlusion of the iliac artery to mimic the glibenclamide-induced attenuation in active hyperemia. This additional finding suggests that functional sympatholysis is not simply a matter of contractioninduced metabolic vasodilation overwhelming sympathetic vasoconstriction, but rather, that it is linked specifically to activation of $\mathrm{K}_{\mathrm{ATP}}$ channels.

While the glibenclamide-sensitive potassium channels mediating functional sympatholysis are most likely those located in vascular smooth muscle (38), $\mathrm{K}_{\mathrm{ATP}}$ channels in other tissues such as skeletal muscle (39) and vascular endothelium (40) could also be involved. Glibenclamide also blocks $\mathrm{K}_{\mathrm{ATP}}$ channels in pancreatic $\beta$ cells (41), resulting in the increased release of insulin. In the present experiments, we negated the insulininduced hypoglycemia with 5\% dextrose (42). In humans, however, euglycemic hyperinsulinemia has been shown to cause vasodilation in skeletal muscle $(43,44)$ and to attenuate sympathetic vasoconstriction by interfering primarily with $\alpha_{2^{-}}$ adrenergic vasoconstriction (45). During rat hindlimb muscle contraction, however, glibenclamide-induced augmentation of sympathetic vasoconstriction was a robust phenomenon despite any potentially confounding effect of insulin-mediated vasodilation.
The precise metabolic events in contracting skeletal muscle that activate $\mathrm{K}_{\mathrm{ATP}}$ channels are not known. In pancreatic $\beta$ cells, $\mathrm{K}_{\mathrm{ATP}}$ channels are activated by decreases in intracellular ATP (46). However, changes in the intracellular concentration of ATP are unlikely to play a primary role in contractioninduced inhibition of sympathetic vasoconstriction, since ATP concentrations are well maintained, even during ischemic contraction (47). In contrast, contracting skeletal muscle produces a number of metabolites that have been postulated to act at least in part by opening $\mathrm{K}_{\mathrm{ATP}}$ channels. These include hydrogen ion (48), lactate (49), adenosine (14-18), prostacyclin (21, $22)$, and nitric oxide $(19,20)$. In addition, skeletal muscle hypoxia also could play an important role in $\mathrm{K}_{\mathrm{ATP}}$ channel activation during contraction. The vasodilator response in intact animals to systemic hypoxia (17), as well as to local hypoxia induced by ischemia (50), has been shown to be sensitive to inhibition by glibenclamide.

In conclusion, we have shown that blockade of $\mathrm{K}_{\mathrm{ATP}}$ channels with the antidiabetic sulphonylurea glibenclamide exerts a detrimental effect on blood flow to exercising skeletal muscles by both $(a)$ reducing active hyperemia and $(b)$ potentiating the vasoconstrictor response to sympathetic activation, which normally is greatly attenuated in contracting muscles. Thus, $\mathrm{K}_{\mathrm{ATP}}$ channels appear to play a central role in the precise regulation of blood flow to contracting muscles in the rat. It is not known whether a similar role for $\mathrm{K}_{\mathrm{ATP}}$ channels exists in humans. However, a single therapeutic dose of oral glibenclamide has been shown to decrease baseline calf blood flow in normal human subjects (51). Based on our experimental findings in rats, we speculate that in the clinical setting, the use of sulphonylurea derivatives in patients with non-insulin-dependent diabetes mellitus may exert detrimental effects on the regulation of peripheral blood flow during exercise, and in so doing, potentially contribute to diabetic vasculopathy.

\section{Acknowledgments}

We thank Dr. Jere H. Mitchell for his continued support and critical review of our work.

This research was supported by a grant to Dr. Victor from the National Institutes of Health (P01-HL-06296) and to Dr. Thomas from the American Heart Association, Texas Affiliate (96G-064). Dr. Hansen was supported by a Fogarty International Research Fellowship (NIH-1-F05-TW04949-01) and grants from the Danish Heart Foundation, The Simonsen \& Weel Foundation, and the Danish Research Academy.

\section{References}

1. McGillivray-Anderson, K.M., and J.E. Faber. 1990. Effect of acidosis on contraction of microvascular smooth muscle by $\alpha_{1}$ - and $\alpha_{2}$-adrenoceptors: implications for neural and metabolic regulation. Circ. Res. 66:1643-1657.

2. McGillivray-Anderson, K.M., and J.E. Faber. 1991. Effect of reduced blood flow on $\alpha_{1}$ - and $\alpha_{2}$-adrenoceptor constriction of rat skeletal muscle microvessels. Circ. Res. 69:165-173.

3. Medgett, I.C., P.E. Hicks, and S.Z. Langer. 1987. Effect of acidosis on $\alpha_{1}$ and $\alpha_{2}$-adrenoceptor-mediated vasoconstrictor responses in isolated arteries. Eur. J. Pharmacol. 135:443-447.

4. Tateishi, J., and J.E. Faber. 1995. Inhibition of arteriole $\alpha_{2}$ - but not $\alpha_{1}$ adrenoceptor constriction by acidosis and hypoxia in vitro. Am. J. Physiol. 268 (Heart Circ. Physiol. 37):H2068-H2076.

5. Thomas, G.D., J. Hansen, and R.G. Victor. 1994. Inhibition of $\alpha_{2}$-adrenergic vasoconstriction during contraction of glycolytic, not oxidative, rat hindlimb muscle. Am. J. Physiol. 266(Heart Circ. Physiol. 35):H920-H929.

6. Hansen, J., G.D. Thomas, S.A. Harris, W.J. Parsons, and R.G. Victor. 1996. Differential sympathetic neural control of oxygenation in resting and exercising human skeletal muscle. J. Clin. Invest. 98:584-596. 
7. Remensnyder, J.P., J.H. Mitchell, and S.J. Sarnoff. 1962. Functional sympatholysis during muscular activity. Circ. Res. 11:370-380.

8. Timmermans, P.B.M.W.M., A.T. Chiu, and M.J.M.C. Thoolen. 1987. Calcium handling in vasoconstriction to stimulation of alpha ${ }_{1}$ - and $\mathrm{alpha}_{2}$-adrenoceptors. Can. J. Physiol. Pharmacol. 65:1649-1657.

9. Minneman, K.P. 1988. $\alpha_{1}$-adrenergic receptor subtypes, inositol phosphates, and sources of cell $\mathrm{Ca}^{2+}$. Pharmacol. Rev. 40:87-119.

10. Mironneau, J., and N. Macrez-Lepretre. 1995. Modulation of $\mathrm{Ca}^{2+}$ channels by $\alpha_{1 \mathrm{~A}^{-}}$and $\alpha_{2 \mathrm{~A}}$-adrenoceptors in vascular myocytes: involvement of different transduction pathways. Cell. Signal. 7:471-479.

11. Nelson, M.T., and J.M. Quayle. 1995. Physiological roles and properties of potassium channels in arterial smooth muscle. Am. J. Physiol. 268(Cell Physiol. 37):C799-C822.

12. Quayle, J.M., and N.B. Standen. 1994. $\mathrm{K}_{\mathrm{ATP}}$ channels in vascular smooth muscle. Cardiovasc. Res. 28:797-804.

13. Quast, U., J.-M. Guillon, and I. Cavero. 1994. Cellular pharmacology of potassium channel openers in vascular smooth muscle. Cardiovasc. Res. 28 : $805-810$

14. Beckerath, von, N., S. Cyrys, A. Dischner, and J. Daut. 1991. Hypoxic vasodilatation in isolated, perfused guinea-pig heart: an analysis of the underlying mechanisms. J. Physiol. 442:297-319.

15. Jackson, W.F. 1993. Arteriolar tone is determined by activity of ATPsensitive potassium channels. Am. J. Physiol. 265(Heart Circ. Physiol. 34): H1797-H1803.

16. Kleppisch, T., and M.T. Nelson. 1995. Adenosine activates ATP-sensitive potassium channels in arterial myocytes via $\mathrm{A}_{2}$ receptors and cAMP-dependent protein kinase. Proc. Natl. Acad. Sci. USA. 92:12441-12445.

17. Marshall, J.M., T. Thomas, and L. Turner. 1993. A link between adenosine, ATP-sensitive $\mathrm{K}^{+}$channels, potassium, and muscle vasodilatation in the rat in systemic hypoxia. J. Physiol. 472:1-9.

18. Nakhostine, N., and D. Lamontagne. 1993. Adenosine contributes to hypoxia-induced vasodilatation through ATP-sensitive $\mathrm{K}^{+}$channel activation. Am. J. Physiol. 265(Heart Circ. Physiol. 34):H1289-H1293.

19. Tare, M., H.C. Parkington, H.A. Coleman, T.O. Neild, and G.J. Dusting. 1990. Hyperpolarization and relaxation of arterial smooth muscle caused by nitric oxide derived from the endothelium. Nature (Lond.). 346:69-71.

20. Murphy, M.E., and J.E. Brayden. 1995. Nitric oxide hyperpolarizes rabbit mesenteric arteries via ATP-sensitive potassium channels. J. Physiol. 486: $47-58$

21. Jackson, W.F., A. Konig, T. Dambacher, and R. Busse. 1993. Prostacyclin-induced vasodilation in rabbit heart is mediated by ATP-sensitive potassium channels. Am. J. Physiol. 264(Heart Circ. Physiol. 33):H238-H243.

22. Bouchard, J.-F., E. Dumont, and D. Lamontagne. 1994. Evidence that prostaglandins I2, E2, and D2 may activate ATP sensitive potassium channels in the isolated rat heart. Cardiovasc. Res. 28:901-905.

23. Mori, H., M. Chujo, E. Tanaka, A. Yamakawa, Y. Shinozaki, M.-U. Mohamed, and H. Nakazawa. 1995. Modulation of adrenergic coronary vasoconstriction via ATP-sensitive potassium channel. Am. J. Physiol. 268(Heart Circ. Physiol. 37):H1077-H1085.

24. Nakai, T., and K. Ichihara. 1994. Effects of diazoxide on norepinephrine-induced vasocontraction and ischemic myocardium in rats. Biol. Pharm. Bull. 17:1341-1343.

25. Tateishi, J., and J.E. Faber. 1995. ATP-sensitive $\mathrm{K}^{+}$channels mediate $\alpha_{2 \mathrm{D}}$-adrenergic receptor contraction of arteriolar smooth muscle and reversal of contraction in hypoxia. Circ. Res. 76:53-63.

26. Randall, M.D., and A.I. McCulloch. 1995. The involvement of ATP-sensitive potassium channels in $\beta$-adrenoceptor-mediated vasorelaxation in the rat isolated mesenteric arterial bed. Br. J. Pharmacol. 115:607-612.

27. Narishige, T., K. Egashira, Y. Akatsuka, Y. Imamura, T. Takahashi, H. Kasuya, and A. Takeshita. 1994. Glibenclamide prevents coronary vasodilation induced by $\beta_{1}$-adrenoceptor stimulation in dogs. Am. J. Physiol. 266(Heart Circ. Physiol. 35):H84-H92.

28. Vanelli, G., and S.N.A. Hussain. 1994. Effects of potassium channel blockers on basal vascular tone and reactive hyperemia of canine diaphragm. Am. J. Physiol. 266(Heart Circ. Physiol. 35):H43-H51.

29. Minkes, R.K., J.A. Santiago, T.J. McMahon, and P.J. Kadowitz. 1995. Role of $\mathrm{K}^{+}$ATP channels and EDRF in reactive hyperemia in the hindquarters vascular bed of cats. Am. J. Physiol. 269(Heart Circ. Physiol. 38):H1704-H1712.

30. Gopalakrishnan, M., and D.J. Triggle. 1992. Regulation of ATP-sensi- tive $\mathrm{K}^{+}$channels by chronic glyburide and pinacidil administration. Biochem. Pharmacol. 44:1843-1847.

31. Rohmann, S., H. Weygandt, P. Schelling, L.K. Soei, K.H. Becker, P.D. Verdouw, I. Lues, and G. Hausler. 1994. Effect of bimakalim (EMD 52692), an opener of ATP sensitive potassium channels, on infarct size, coronary blood flow, regional wall function, and oxygen consumption in swine. Cardiovasc. Res. 28:858-863.

32. Soares-da-Silva, P. and M.H. Fernandes. 1990. Inhibition by the putative potassium channel opener pinacidil of the electrically-evoked release of endogenous dopamine and noradrenaline in the rat vas deferens. NaunynSchmiedeberg's Arch. Pharmacol. 342:415-421.

33. Takata, Y., F. Shimada, and H. Kato. 1992. Differential effects of diaz oxide, cromakalim and pinacidil on adrenergic neurotransmission and ${ }^{86} \mathrm{Rb}^{+}$efflux in rat brain cortical slices. J. Pharmacol. Exp. Ther. 263:1293-1301.

34. Kalsner, S. 1995. Hypoxic relaxation in functionally intact cattle coronary artery segments involves $\mathrm{K}^{+}{ }_{\text {ATP }}$ channels. J. Pharmacol. Exp. Therap. 275 : 1219-1226.

35. Comtois, A., C. Sinderby, N. Comtois, A. Grassino, and J.M. Renaud. 1994. An ATP-sensitive potassium channel blocker decreases diaphragmatic circulation in anesthetized dogs. J. Appl. Physiol. 77:127-134.

36. Vanelli, G., H.Y. Chang, A.G. Gatensby, and S.N.A. Hussain. 1994. Contribution of potassium channels to active hyperemia of the canine diaphragm. J. Appl. Physiol. 76:1098-1105.

37. Saito, Y., M. McKay, A. Eraslan, and R.L. Hester. 1996. Functional hyperemia in striated muscle is reduced following blockade of ATP-sensitive potassium channels. Am. J. Physiol. 270(Heart Circ. Physiol. 39):H1649-H1654.

38. Standen, N.B., J.M. Quayle, N.W. Davies, J.E. Brayden, Y. Huang, and M.T. Nelson. 1989. Hyperpolarising vasodilators activate ATP-sensitive $\mathrm{K}^{+}$ channels in arterial smooth muscle. Science (Wash. DC). 245:177-180.

39. Spruce, A.E., N.B. Standen, and P.R. Stanfield. 1985. Voltage dependent ATP sensitive potassium channels of skeletal muscle membrane. Nature (Lond.). 316:736-738

40. Jangiro, D., G.A. West, E.L. Gordon, and H.R. Winn. 1993. ATP-sensitive $\mathrm{K}^{+}$channels in rat aorta and brain microvascular endothelial cells. Am. J. Physiol. 265(Cell Physiol. 34):C812-C821.

41. Schmid-Antomarchi, H., J. De Weille, M. Fosset, and M. Lazdunski. 1987. The receptor for antidiabetic sulfonylureas controls the activity of the ATP-modulated $\mathrm{K}^{+}$channel in insulin-secreting cells. J. Biol. Chem. 262:1584015844.

42. Moreau, R., H. Komeichi, P. Kirstetter, S. Yang, B. Aupetit-Faisant, S Cailmail, and D. Lebrec. 1994. Effects of glibenclamide on systemic and splanchnic haemodynamics in conscious rats. Br. J. Pharmacol. 112:649-653.

43. Creager, M.A., C.S. Liang, J.D. Coffman. 1985. Beta adrenergic-mediated vasodilator response to insulin in the human forearm. J. Pharmacol. Exp. Ther. 235:709-714.

44. Anderson, E.A., R.P. Hoffman, T.W. Balon, C.A. Sinkey, and A.L. Mark. 1991. Hyperinsulinemia produces both sympathetic neural activation and vasodilation in normal humans. J. Clin. Invest. 87:2246-2252.

45. Lembo, G., G. Iaccarino, V. Rendina, M. Volpe, and B. Trimarco. 1994. Insulin blunts sympathetic vasoconstriction through the $\alpha_{2}$-adrenergic pathway in humans. Hypertension (Dallas). 24:429-438.

46. Cook, D., and C. Hales. 1984. Intracellular ATP directly blocks $\mathrm{K}^{+}$ channels in pancreatic B-cells. Nature (Lond.). 311:271-273.

47. Miller, R.G., M.D. Boska, R.S. Moussavi, P.J. Carson, and M.W. Weiner. 1988. ${ }^{31} \mathrm{P}$ nuclear magnetic resonance studies of high energy phosphates and $\mathrm{pH}$ in human muscle fatigue. Comparison of aerobic and anaerobic exercise. J. Clin. Invest. 81:1190-1196.

48. Davies, N.W. 1990. Modulation of ATP-sensitive $\mathrm{K}^{+}$channels in skeletal muscle by intracellular protons. Nature (Lond.). 343:375-377.

49. Keung, E.C., and Q. Li. 1991. Lactate activates ATP-sensitive potassium channels in guinea pig ventricular myocytes. J. Clin. Invest. 88:1772-1777.

50. Vallet, B., S.E. Curtis, B. Guery, J. Mangalaboyi, P. Menager, S.M Cain, C. Chopin, and B.A. Dupuis. 1995. ATP-sensitive $\mathrm{K}^{+}$channel blockade impairs $\mathrm{O}_{2}$ extraction during progressive ischemia in pig hindlimb. J. Appl. Physiol. 79:2035-2042.

51. Kosmas, E.N., R.D. Levy, and S.N.A. Hussain. 1995. Acute effects of glyburide on the regulation of peripheral blood flow in normal humans. Eur. J. Pharmacol. 274:193-199. 